\title{
How do personal and professional characteristics influence the development of psychotherapists in training: Results from a longitudinal study
}

\author{
Oliver Evers, ${ }^{1,2}$ Paul Schröder-Pfeifer, ${ }^{1}$ Heidi Möller, ${ }^{3}$ Svenja Taubner ${ }^{1}$ \\ ${ }^{1}$ Institute for Psychosocial Prevention, Heidelberg University Hospital, Heidelberg; ${ }^{2}$ Department of Psychology, Heidelberg University, \\ Heidelberg; ${ }^{3}$ Department of Psychology, University of Kassel, Kassel, Germany
}

Correspondence: Oliver Evers, Institute for Psychosocial Prevention, Heidelberg University Hospital, Bergheimer Str. 54, D-69115 Heidelberg, Germany.

Tel.: +49.6221564771.

Fax: +49.6221564702 .

E-mail: oliver.evers@med.uni-heidelberg.de

Citation: Evers, O., Schröder-Pfeifer, P, Möller, H., \& Taubner, S. (2019). How do personal and professional characteristics influence the development of psychotherapists in training? Results from a longitudinal study. Research in Psychotherapy: Psychopathology, Process and Outcome, 22(3), 389-401. doi:10.4081/ ripppo.2019.424.

Acknowledgements: This study was funded by the German Research Foundation (DFG). We would like to thank all cooperating training programs and trainees for devoting their time and effort to this study. We are grateful to the contributions of Christian Curth, Birgit Proll, Wiebke Hanke, Jennifer Klasen, Daniela Michaelis, Thomas Munder, and Silke Wolter on the research team and all student assistants for making this study possible.

Contributions: OE conceptualized the specific research question; he was the main author of the introduction and discussion section; he wrote major parts of the methods and minor parts of the results section and designed the tables and conducted parts of the statistical analyses. PSF conducted the central part of the statistical analyses and was the main author of the statistical analysis and results section. HM designed the overall study and provided input for the discussion and results section and conducted corrections on said sections. ST designed and coordinated the overall study. She wrote parts of the introduction, methods, and discussion section. She provided input on the specific research question and corrected the overall paper.

Conflict of interest: The authors declare no potential conflict of interest.

Funding: German Research Foundation (DFG); Grant numbers: MO 2008/2-1; MO 2008/2-2.

Received for publication: 12 August 2019.

Revision received: 8 November 2019.

Accepted for publication: 10 November 2019.

This work is licensed under a Creative Commons Attribution NonCommercial 4.0 License (CC BY-NC 4.0).

${ }^{\circ}$ Copyright: the Author(s), 2019

Licensee PAGEPress, Italy

Research in Psychotherapy:

Psychopathology, Process and Outcome 2019; 22:389-401

doi:10.4081/ripppo.2019.424

\begin{abstract}
This study examined the professional development of psychotherapy trainees over three years of training. The first objective was to investigate the long-term change of work involvement (Healing and Stressful Involvement) during psychotherapy training. The second objective was to investigate possible predictors of professional development from the areas of training context as well as professional and personal attributes of trainees. A total of 184 psychotherapy trainees with psychodynamic, psychoanalytic and cognitive behavioral orientation participated in the study. The development of work involvement was assessed over three years of training using the Work Involvement Scales. The set of possible predictors for work involvement included training context variables (training orientation, supervision), professional attributes of trainees (theoretical breadth, work satisfaction), and personal attributes of trainees (introject affiliation, attachment strategies, personality traits). Hierarchical Linear Modeling was conducted to investigate the change over time and the individual predictors of work involvement. Over three years of training Healing Involvement improved whereas Stressful Involvement did not change over time. Healing Involvement was mostly predicted by training context variables and professional attributes (therapeutic orientation, job satisfaction) as well as extraversion. Stressful Involvement was only predicted by personal attributes of trainees (age, neuroticism, conscientiousness, introject affiliation). The results imply two distinct sets of predictors for Healing and Stressful Involvement that will be discussed with regard to their implications for psychotherapy training and trainee selection.
\end{abstract}

Key words: Professional development; psychotherapy training; work involvement; therapist characteristics; personality.

\section{Introduction}

In spite of a accumulating evidence on how psychotherapist competence relates to treatment process and outcome (Ackerman \& Hilsenroth, 2001, 2003; Wampold, Baldwin, grosse Holtforth, \& Imel, 2017), little is known about how these attributes develop in training (Hill \& Knox, 2013; Willutzki, Fydrich, \& Strauß, 2015). In research on psychotherapy training the majority of longitudinal studies has focused on the change of model-specific technical skills (e.g. Barnfield, Mathieson, \& Beaumont, 2007; BennettLevy \& Beedie, 2007; Hilsenroth, Defife, Blagys, \& Ack- 
erman, 2006). However, these technical skills are only weakly related to outcome, according to meta-analytic results (Collyer, Eisler, \& Woolgar, 2019; Webb, DeRubeis, $\&$ Barber, 2010). More promising predictors of outcome include relational skills and indicators of global professional development (Bennett-Levy, 2019; Wampold et al., 2017). One indicator for professional development that combines several professional and relational aspects of working with clients is therapist work involvement (Orlinsky \& Rønnestad, 2005). Work involvement is a multidimensional construct that covers different aspects of professional competence and professional development, which have been shown to relate to the therapeutic alliance and outcome (Heinonen, Knekt, Jääskeläinen, \& Lindfors, 2014; Heinonen et al., 2013; Heinonen, Lindfors, Laaksonen, \& Knekt, 2012; Nissen-Lie, Monsen, \& Rønnestad, 2010; Nissen-Lie, Monsen, Ulleberg, \& Rønnestad, 2013; Nissen-Lie et al., 2017).

Despite the impact of work involvement on psychotherapeutic process and outcome, we know too little about how it changes during psychotherapy training, and what factors may contribute to its increase or decrease. Previous studies on work involvement have mainly focused on its cross-sectional development (Orlinsky \& Rønnestad, 2005), included only short observation periods (Dennhag \& Ybrandt, 2013) or focused on some subcomponents only (e.g. Dennhag \& Ybrandt, 2013; Taubner, Zimmermann, Kächele, Möller, \& Sell, 2013). Similarly, several studies have investigated predictors that influence the development of work involvement (Fincke, Möller, \& Taubner, 2015; Messina et al., 2018; Orlinsky \& Rønnestad, 2005), but they have used either cross-sectional designs or included limited sets of predictors, selectively covering either the personal or professional attributes of trainees.

The current study addresses this gap in research by investigating the development of work involvement during three years of psychotherapy training. This study also aims to investigate variables that predict trainees' professional development. Among such variables we present evidence regarding a number of variables, spanning from trainees' training context to their professional and personal attributes.

\section{The construct of work involvement}

Conceptually and operationally, work involvement can be divided into the dimensions of Healing Involvement (i.e. basic relational skills, experience of agency, affirmative relational style, constructive coping) and Stressful Involvement (i.e. frequent difficulties in practice, feelings of anxiety or boredom in working with clients, avoidant coping); these two dimensions seem to have independent associations with distinct aspects of psychotherapy practice. Healing Involvement is conceptually related to elements of the therapeutic relationship (Elliott, Bohart, Watson, \& Murphy, 2018; Farber, Suzuki, \&
Lynch, 2018; Kolden, Wang, Austin, Chang, \& Klein, 2018) and relational competence (Anderson \& Hill, 2017) which contribute significantly to psychotherapy outcome (Norcross \& Lambert, 2018). A subcomponent of Healing Involvement, "Basic relational skills", has also been shown to predict the working alliance in psychodynamic therapies (Heinonen et al., 2013).

The subcomponents of Stressful Involvement (i.e. negative personal reactions to clients and professional selfdoubt) show more complex associations with psychotherapy process and outcome. In a naturalistic longitudinal study of outpatient psychotherapy, the psychotherapists' negative personal reaction to clients had a negative impact on the working alliance with their clients (Nissen-Lie et al., 2010). At the same time, professional self-doubt predicted better working alliances (Nissen-Lie et al., 2010) and superior outcomes with respect to clients' interpersonal problems (Nissen-Lie et al., 2013). The positive effect of professional self-doubt seemed to be due to an interaction with therapists' introject affiliation, given that positive outcomes were achieved by therapists with high introject affiliation and comparatively high levels of professional self-doubt (Nissen-Lie et al., 2017). These results highlight the interaction between personal characteristics (i.e. introject affiliation) and professional characteristics (i.e. professional self-doubt) in psychotherapeutic processes which have yet to be investigated in relation to psychotherapy training.

\section{The development of work involvement}

Previous studies on how therapist work involvement changes over time suggest that its two main components may develop following different trajectories. On one hand, Healing Involvement seems to increase during training. Taubner and colleagues (2013) reported an increase of this variable in 171 trainees with a medium effect size over three years of training. Dennhag and Ybrandt (2013) found a small to large increase on the different subscales of Healing Involvement in 76 trainees over half a year of training. On the other hand, Stressful Involvement does not seem to change during training. The same study by Dennhag and Ybrandt (2013) found a small decline or no change in the subscales of Stressful Involvement during training. A large cross-sectional study by Orlinsky and Rønnestad (2005) also seems to support this conclusion. In this study, more experienced therapists were found to have a higher degree of Healing Involvement while the variance in Stressful Involvement was not explained by therapists' experience.

Qualitative and quantitative empirical results point to a large variation in trainees' professional development. In their short longitudinal study on the change of work involvement, Dennhag and Ybrandt (2013) also examined if each trainee changed reliably or not. Using the Reliable Change Index (RCI; Jacobson \& Truax, 1991), the authors found that the majority of trainees $(65-91 \%)$ showed no 
reliable change in work involvement, whereas 5-11\% improved and 1-8\% deteriorated (Dennhag \& Ybrandt, 2013), which points to variations in trainees' development that go beyond the average effect. Likewise, qualitative studies reported that psychotherapy trainees show varying patterns of indicators of Healing Involvement (i.e. high levels of commitment, positive expectations) and Stressful Involvement (i.e. feelings of insufficiency, anxiety) in the early stages of their career development (Hill, Sullivan, Knox, \& Schlosser, 2007; Kannan \& Levitt, 2017; Rønnestad \& Skovholt, 2013). These variations of Healing and Stressful Involvement could be part of larger positive or negative developmental cycles (Orlinsky \& Rønnestad, 2005; Rønnestad, Orlinsky, Schröder, Skovholt, \& Willutzki, 2019). The varying rates of development might be explained by trainee and training attributes, which we explore in the next section.

\section{Predictors of work involvement}

In previous studies, the most important predictors of work involvement were professional attributes and other aspects of the training context (Orlinsky \& Rønnestad, 2005). Professional attributes were investigated in the previously cited study by Orlinsky and Rønnestad (2005). In this study, Healing Involvement was predicted by theoretical breadth (i.e. integrating different theoretical approaches in therapeutic practice), work satisfaction, and experience in different treatment modalities. Stressful Involvement correlated negatively with work satisfaction and work setting in independent practice. Training variables were investigated in a cross-sectional study among 90 psychotherapy trainees (Messina et al., 2018). The authors found that Healing involvement was positively correlated with the satisfaction with personal therapy (ibid.). They did not find any training variables that predicted Stressful Involvement. Even though these professional and training variables were the most important predictors, most variance in work involvement remained unexplained, which suggests that there are other important predictors of professional development.

Some further predictors that might add to the understanding on how work involvement develops stem from the area of trainees' personal attributes. The only personal attribute that has been investigated as a predictor of work involvement is introject affiliation (Taubner et al., 2013). The concept of introject (Benjamin, 1974) describes how one treats oneself day by day on the dimensions of lovehate (affiliation) and emancipation-control (interdependence). In their study of 171 psychotherapy trainees, Taubner and colleagues (2013) found that introject affiliation correlated positively with Healing Involvement, which points to an important connection between personal attributes and professional development of trainees. However, other personal attributes of trainees that have been linked to the quality of the therapeutic process, like attachment and personality traits (Chapman, Talbot, Tat- man, \& Britton, 2009; de la Fuente Zepeda \& Cruz del Castillo, 2017; Finlay, 2018; Navia \& Arias, 2012; Peter, Böbel, Hagl, Richter, \& Kazén, 2017; Schauenburg et al., 2010), have not been investigated as predictors and deserve further investigation.

An important limitation of previous studies in this field is that professional attributes and training contexts have been mostly investigated separately from personal attributes of trainees. Empirically, previous research points to a significant relationship between these three domains in studies of psychotherapy outcome (Nissen-Lie et al., 2017), training effects (Henry, Schacht, Strupp, Butler, \& Binder, 1993) and trainee attitudes (Taubner, Munder, Möller, Hanke, \& Klasen, 2014). One study that included predictors of Stressful Involvement from several different domains (i.e. psychotherapy process, therapist experience, work context) found that only therapist-related process variables and not length of work experience or context predicted Stressful Involvement (Zeeck et al., 2012). Even though this study did not include personal attributes per se, it shows that therapist variables might explain more variance in work involvement than professional context variables. Thus, it is important to include variables from the professional and training domain as well as personal attributes in one prediction model to evaluate their relative importance.

The current study aims to investigate the development of work involvement over three years of psychotherapy training. In contrast to previous research, this study includes a longitudinal data set and compares the effects of three relevant groups of predictors (i.e. training context, professional attributes and personal attributes of trainees). Since there is little knowledge on long-term changes during training or the relative importance of predictors of work involvement, the study addresses two exploratory questions: i) To what extend do Healing and Stressful Involvement change during three years of psychotherapy training? ii) Which aspects of the training context, professional attributes or personal attributes predict the levels of Healing and Stressful Involvement?

\section{Materials and Methods}

\section{Setting}

The study was conducted in a German training setting. German psychotherapy training is organized as post-graduate specialty training in state-licensed training programs. The entry level requirement for adult psychotherapy training is a 5-year academic degree in clinical psychology. The most common orientations in licensed training programs are psychodynamic, psychoanalytic and cognitivebehavioral. A limited number of institutes also offer training in humanistic or systemic therapy. Programs consist of $4200 \mathrm{~h}$ of training over three to five years that include didactic instruction, personal therapy, clinical 
internships, and outpatient treatments under supervision. More information on German training and practice can be found in Strauß (2009).

\section{Procedure and recruitment}

The current study followed a naturalistic longitudinal design. At the beginning of the study a selection of 29 training programs in adult psychotherapy training were contacted for recruitment, balanced by region and therapeutic orientation. A total of 17 training programs (59\%) agreed to cooperate, including 2 cognitive-behavioral (CBT) programs, 2 psychoanalytic (PA) and 1 psychodynamic (PD) programs as well as 8 programs offering PA and $\mathrm{PD}$ training and 4 training centers that offered several programs in $\mathrm{CBT}$ or $\mathrm{PD} / \mathrm{PA}$. Trainees within the programs were recruited at different stages of their training in order to cover the whole duration of German psychotherapy training. The pre-post measurements were conducted at the beginning of the study (T1) and after three years (T2). The study was approved by the ethics committee of the University of Kassel, Germany.

\section{Sample}

The sample included 184 trainees at $\mathrm{T} 1$ and 130 Trainees at T2 (29.3\% dropout). Table 1 shows the sample characteristics according to orientation. Trainees in CBT training make up $34.8 \%(n=64)$ of the sample, $47.3 \%$ $(n=87)$ were in psychodynamic training, and $17.9 \%$ $(n=33)$ of trainees were in psychoanalytic training. The trainees had completed an average of 2.3 semesters $(S D=1.82$; range $=1-12)$. The mean age was 31.42 years $(S D=6.67$; range $=24-55), 84.2 \%$ were female.

Trainees of different orientations differed significantly in age $(F(2,181)=5.07 ; \mathrm{P}=.007)$ and semester $(F(2$, $181)=13.40 ; \mathrm{P}<.001)$. CBT candidates were significantly younger than $\mathrm{PA}(\Delta=4.10 ; \mathrm{P}=.01)$ and $\mathrm{PD}$ trainees $(\Delta=2.60 ; \mathrm{P}=.04)$. PA trainees in the sample were in a higher semester than CBT $(\Delta=1.71 ; \mathrm{P}<.001)$ and $\mathrm{PD}$ trainees $(\Delta=1.69 ; \mathrm{P}<.001)$. Study dropouts differed significantly by therapy orientation $\left(\chi^{2}(2)=12.07 ; \mathrm{P}=.002\right)$. CBT candidates were more likely to drop out $(z=3.5), \mathrm{PD}$ candidates dropped out less frequently $(z=2.4)$. Additionally, dropouts differed in openness to experience ( $\Delta=1.73$;
$T(182)=1.98 ; \mathrm{P}=.05)$, with dropouts being less open to experience. There was no difference on any other outcome or predictor variable.

\section{Measures}

Work Involvement Scales (WIS; Orlinsky \& Ronnestad, 2005)

The professional development of trainees was assessed via the WIS. The WIS is a self-report questionnaire to assess professional development in psychotherapists. It contains 52 items that form a total of 10 subscales. These subscales reflect therapeutic skills, relational agency, relational manner, feelings in therapeutic sessions, difficulties in practice, and coping strategies. The scales form the two superordinate constructs "Healing Involvement" and "Stressful Involvement". In the current study, both higher-order scales had acceptable to good internal consistencies $(\alpha=.76-.82)$.

Therapeutic Attitudes Scales (TASC-2) - trainee version (Sandell, Taubner, Rapp, Visbeck, \& Kächele, 2008)

The TASC-2 was used to assess training context variables and professional attributes. It is a self-report instrument that assesses therapeutic attitudes such as basic assumptions and beliefs about psychotherapy (Sandell et al., 2004). The trainee version was adapted to assess variables relevant for the therapy training setting (Sandell et al., 2008). Among these variables, training context, theoretical breadth and satisfaction with supervision were assessed for this study. Trainees reported their satisfaction with each aspect of the training on a 5-point scale. Additionally, trainees were offered a list of 8 different approaches and used a 5-point scale to indicate the extent to which they integrated these approaches in their personal orientation. A sum score for theoretical breadth was formed by counting the number of orientations that were integrated to "some degree" or higher (scores 3-5).

\section{Questions on Life Satisfaction (FLZM; Henrich \& Herschbach, 2000)}

The professional attribute work satisfaction was assessed with the FLZ ${ }^{\mathrm{M}}$ questionnaire. The FLZ ${ }^{\mathrm{M}}$ assesses the satisfaction with eight areas of life using two items

Table 1. Demographic data by therapy orientation.

\begin{tabular}{|c|c|c|c|c|c|c|}
\hline & $\begin{array}{c}\text { CBT } \\
(n=64)\end{array}$ & $\begin{array}{c}\text { PD } \\
(n=87)\end{array}$ & $\begin{array}{c}\text { PA } \\
(n=33)\end{array}$ & $\begin{array}{c}\text { Total } \\
(n=184)\end{array}$ & \multicolumn{2}{|c|}{$\begin{array}{c}\text { Differences by } \\
\text { orientation }\end{array}$} \\
\hline $\begin{array}{l}\text { Age, mean (SD) } \\
P=.007\end{array}$ & $29.49(5.29)$ & $31.83(7.14)$ & 33.79 (6.98) & $31.42(6.67)$ & $F(2$, & 181)=5.07; \\
\hline Gender (female), \% & 84.4 & 85.1 & 81.8 & 84.2 & \multicolumn{2}{|c|}{$\chi^{2}(2)=.19 ; P=.91$} \\
\hline $\begin{array}{l}\text { Semester, mean (SD) } \\
P<.001\end{array}$ & $2.00(1.71)$ & $1.98(1.35)$ & $3.49(2.32)$ & $2.30(1.82)$ & $F(2$, & $181)=13.40$ \\
\hline
\end{tabular}

$\mathrm{CBT}=$ cognitive behavioral therapy $; \mathrm{PD}=$ psychodynamic therapy; $\mathrm{PA}=$ psychoanalytic therapy. 
per area. One item is used to assess the subjective importance of each area on a 5-point scale, a second item is used to report the satisfaction with that area of life on a 4-point scale. Importance scores are used to create an index of "weighted satisfaction" for each area of life, ranging from -12 to +20 . The internal consistency of the $\mathrm{FLZ}^{\mathrm{M}}$ is high $(\alpha=.82$ - .89; Henrich \& Herschbach, 2000).

\section{NEO Five Factor Inventory (NEO-FFI; Borkenau \& Ostendorf, 1993; Costa \& McCrae, 1992)}

The NEO-FFI was used to assess personal attributes of trainees, namely personality traits. The instrument is a multidimensional personality inventory. It contains 60 items that are being rated on a 5-point scale. These items form 5 scales with 12 items each: "neuroticism", "extraversion", "openness to experience", "agreeableness", and "conscientiousness". The internal consistency of the German translation ranged from $\alpha=.63$ for openness to $\alpha=.83$ for neuroticism and the original factor structure could be replicated (Körner, Geyer, \& Brähler, 2002).

\section{Intrex Questionnaire short form (Benjamin, 1995)}

The personal attribute introject affiliation was assessed with the short form of the Intrex questionnaire. It is a selfreport measure based on the SASB cluster model (Benjamin, Rothweiler, \& Critchfield, 2006) that proposes two cluster surfaces to classify interpersonal behavior and one introject surface that reflects internal actions directed towards oneself (introjection). Introjection is being classified on an "affiliation" axis (self-love $v s$. self-attack) and an "interdependence" axis (self-emancipation vs. selfcontrol) which can be combined to form eight clusters. Participants are being asked to rate their self-directed behaviors during their best times and during their worst times (introject at best; introject at worst). Each cluster is represented by one item. The original item scaling $(0-100)$ has been modified to range from $0-6$ and the clusters were aggregated into vector scores, following the recommendations of Pincus, Newes, Dickinson, and Ruiz (1998). Cronbach's alphas in this study were acceptable for introject affiliation at best $(\alpha=.72)$ and introject affiliation at worst $(\alpha=$.79).

\section{Experiences in Close Relationships Revised (ECR-RD; Ehrenthal, Dinger, Lamla, Funken, \& Schauenburg, 2009)}

The ECR-RD was used to assess personal attributes of trainees. It is a self-report questionnaire on attachment strategies. It contains 36 items that are divided into the scales "attachment anxiety" and "attachment avoidance". It has shown a good construct validity and a very good internal consistency ( $\alpha=.91-.92$; Ehrenthal et al., 2009).

\section{Statistical analysis}

Statistical analyses were conducted utilizing R (Version 3.6.1) and SPSS for Windows (Version 25). The data con- tained $4.27 \%$ missing values. Visual inspection of patternplots as well as sequential t-tests between the group of participants with missing values and without did not suggest systematic missing patterns. Accordingly, missing data was imputed assuming MAR using multiple imputation by chained equations, implemented in the MICE package.

Two multilevel models were computed predicting Healing Involvement and Stressful Involvement at T2. Time was added as a level 1 fixed effect while predictors of the training context (orientation, satisfaction with supervision), professional attributes (work satisfaction, theoretical breadth) and personal attributes of the participants (personality traits, introject affiliation at best and worst, attachment anxiety and avoidance) were added to the model at level 2. Additionally, sex, age, and training semester were controlled for as covariates. Restricted Maximum Likelihood was utilized as estimator in all models. Confidence intervals and significance was computed using Kenward-Roger approximation (Kenward \& Roger, 1997). Visual inspection of QQ-plots and plots of the residuals vs. the fitted data did not hint at significant nonnormality or heteroscedasticity. To examine reliable change in work involvement from T1 to T2, Reliable Change Indices (RCI; Jacobson \& Truax, 1991) were computed.

\section{Results}

\section{Descriptive data}

Descriptive data on predictor and criterion variables are listed in Tables 1 and 2. Table 3 shows the correlations between variables used in the models. Healing Involvement at $\mathrm{T} 1$ correlates positively with extraversion $(r=.29$; $\mathrm{P}<.001$; two-tailed), conscientiousness ( $r=.20 ; \mathrm{P}=.006)$, introject affiliation at best $(r=.31 ; \mathrm{P}<.001)$ and introject affiliation at worst $(r=.31 ; \mathrm{P}<.001)$ and negatively with neuroticism $(r=-.26 ; \mathrm{P}<.001)$, as well as attachment anxiety $(r=-.20 ; \mathrm{P}=.006)$. Healing Involvement at T2 only shows a small to moderate positive correlation with work satisfaction $(r=.27 ; \mathrm{P}<.001)$. Stressful Involvement at T1 is associated with neuroticism $(r=.45 ; \mathrm{P}<.001)$, agreeableness $(r=.26 ; \mathrm{P}<.001)$ and attachment anxiety $(r=.23$; $\mathrm{P}=.002)$ while it shows negative correlations with age $(r=$ $-.24 ; \mathrm{P}=.001)$, conscientiousness $(r=-.24 ; \mathrm{P}=.001)$, introject affiliation at best $(r=-.31 ; \mathrm{P}<.001)$ and at worst $(r=-$ $.32 ; \mathrm{P}<.001)$. Stressful Involvement at $\mathrm{T} 2$ relates to neuroticism $(r=.25 ; \mathrm{P}=.001)$, introject affiliation at best $(r=.21 ; \mathrm{P}=.004)$ and attachment anxiety $(r=.24 ; \mathrm{P}=.001)$ and correlates negatively with conscientiousness $(r=-.25$; $\mathrm{P}=.001)$. Correlations between pre and post measurements are small to moderate, being at $\mathrm{r}=.26(\mathrm{P}<.001)$ for Stressful Involvement and $\mathrm{r}=.29$ for Healing Involvement. At single time points the two constructs of Healing and Stressful Involvement show a small (T2: $\mathrm{r}=-.23 ; \mathrm{P}=.002)$ to moderate $(\mathrm{T} 1: \mathrm{r}=-.35 ; \mathrm{P}<.001)$ negative correlation. 


\section{Change and predictors of work involvement}

Table 4 shows parameter estimates for both models. Healing Involvement increases significantly over three years of training $[\beta=1.09 ; 95 \% \mathrm{CI}(0.76-1.42) ; \mathrm{P}<.001$; $d=.56$; Figure 1]. None of the covariates have a significant effect on Healing Involvement. Among the training context variables, there is a significant main effect of therapeutic orientation as well as an orientation by time interaction. PA orientation predicted Healing Involvement positively $(\beta=0.49 ; 95 \%$ CI $(0.00-0.98) ; \mathrm{P}<.05)$. CBT trainees show a larger increase over time than PA $(\beta=-$ $0.67 ; 95 \% \mathrm{CI}(-1.23--0.11) ; \mathrm{P}=.021)$ and $\mathrm{PD}$ trainees $(\beta=$ $-0.44 ; 95 \% \mathrm{CI}(-0.87--0.01) ; \mathrm{p}=.047)$. Among professional attributes, work satisfaction has a positive effect on Healing Involvement $(\beta=0.02 ; 95 \% \mathrm{CI}(0.00-0.04)$; $\mathrm{P}=.020)$. Among personal attributes, extraversion is associated with higher levels of Healing Involvement $(\beta=0.03$; 95\% CI(0.00-0.06); $\mathrm{P}=.040)$.

Stressful Involvement does not change significantly over time $(\beta=-0.30 ; 95 \% \mathrm{CI}(-0.78-0,18) ; \mathrm{P}=.22 ; d=.04)$. With regard to the covariates, age has a significant effect with older participants scoring lower on Stressful Involvement $(\beta=-0.04 ; 95 \% \mathrm{CI}(-0.06--0.01) ; \mathrm{P}=.008)$. None of the training variables or professional attributes has a significant effect on Stressful Involvement. Among personal attributes of the participants, neuroticism is associated with more Stressful Involvement $(\beta=0.05 ; 95 \% \mathrm{CI}(0.03$ $0.08) ; \mathrm{P}<.001)$ while conscientiousness $(\beta=-0.04 ; 95 \%$ $\mathrm{CI}(-0.07-0.00) ; \mathrm{P}=.040)$ and introject affiliation at best $(\beta=-0.01 ; 95 \% \mathrm{CI}(-0.02-0.00) ; \mathrm{P}=.022)$ are associated with lower levels of Stressful Involvement.

According to the Reliable Change Index, 25 participants $(19.2 \%)$ showed reliable improvement in Healing
Involvement while 105 (80.8\%) participants showed no reliable change. Applying the cut-off value for Healing Involvement (Orlinsky \& Rønnestad, 2005), 86 (66.2\%) participants displayed a high Healing Involvement at T1. This increased to 113 participants $(86.9 \%)$ at T2. The RCI for Stressful Involvement indicates a reliable improvement for 13 participants $(10.0 \%)$, no reliable change for $100(76.9 \%)$ participants and a reliable deterioration for 17 participants $(13.1 \%)$. At T1, 51 participants $(39.2 \%)$ were above the cut-off for heightened stressful involvement, which marginally increased to 54 participants $(41.5 \%)$ at T2.

\section{Discussion}

This study found a positive development of Healing Involvement and a stagnation of Stressful Involvement over three years of psychotherapy training. While the overall sample increased in Healing Involvement with a medium effect size, only one fifths of trainees showed a reliable improvement and the rest of the sample did not improve reliably. After three years of training the majority of trainees were above the cutoff for high Healing Involvement. Stressful Involvement did not change in the overall sample. While the majority of trainees did not change reliably on Stressful Involvement, a small number of trainees showed a reliable improvement or a reliable deterioration. More than a third of trainees were above the cutoff for high Stressful Involvement after three years of training $(41.5 \%)$.

Differences between trainees in the development of work involvement could be explained with predictors from three domains (training context, personal attributes,

Table 2. Descriptive data on predictor and criterion variables.

\begin{tabular}{|c|c|c|c|c|}
\hline & $M$ & $S D$ & Min & $\operatorname{Max}$ \\
\hline \multicolumn{5}{|l|}{ Training context } \\
\hline Satisfaction with supervision (T2) & 4.05 & 0.86 & 1 & 5 \\
\hline \multicolumn{5}{|l|}{ Professional attributes } \\
\hline Theoretical breadth (T1) & 4.75 & 1.49 & 0 & 8 \\
\hline Work satisfaction (T2) & 7.04 & 6.54 & -12.00 & 20.00 \\
\hline \multicolumn{5}{|l|}{ Personal attributes } \\
\hline Neuroticism (T1) & 20.52 & 7.59 & 3 & 41 \\
\hline Extraversion (T1) & 30.61 & 5.31 & 17 & 44 \\
\hline Openness to experience (T1) & 36.03 & 5.43 & 16 & 47 \\
\hline Agreeableness (T1) & 35.37 & 5.07 & 19 & 48 \\
\hline Conscentiousness (T1) & 31.55 & 5.64 & 16 & 43 \\
\hline Introject affiliation at best (T1) & 71.08 & 20.00 & -3.30 & 100.00 \\
\hline Introject affiliation at worst (T1) & 23.22 & 39.26 & -70.50 & 96.30 \\
\hline Attachment anxiety (T1) & 2.51 & 1.02 & 1.00 & 5.11 \\
\hline Attachment avoidance (T1) & 2.19 & 0.82 & 1.00 & 6.11 \\
\hline \multicolumn{5}{|l|}{ Work involvement } \\
\hline Healing Involvement (T1) & 10.34 & 1.16 & 7.08 & 12.88 \\
\hline Healing Involvement (T2) & 11.08 & 1.04 & 7.44 & 13.96 \\
\hline Stressful Involvement (T1) & 4.74 & 1.50 & 1.45 & 9.23 \\
\hline Stressful Involvement (T2) & 4.82 & 1.55 & 0.95 & 10.77 \\
\hline
\end{tabular}




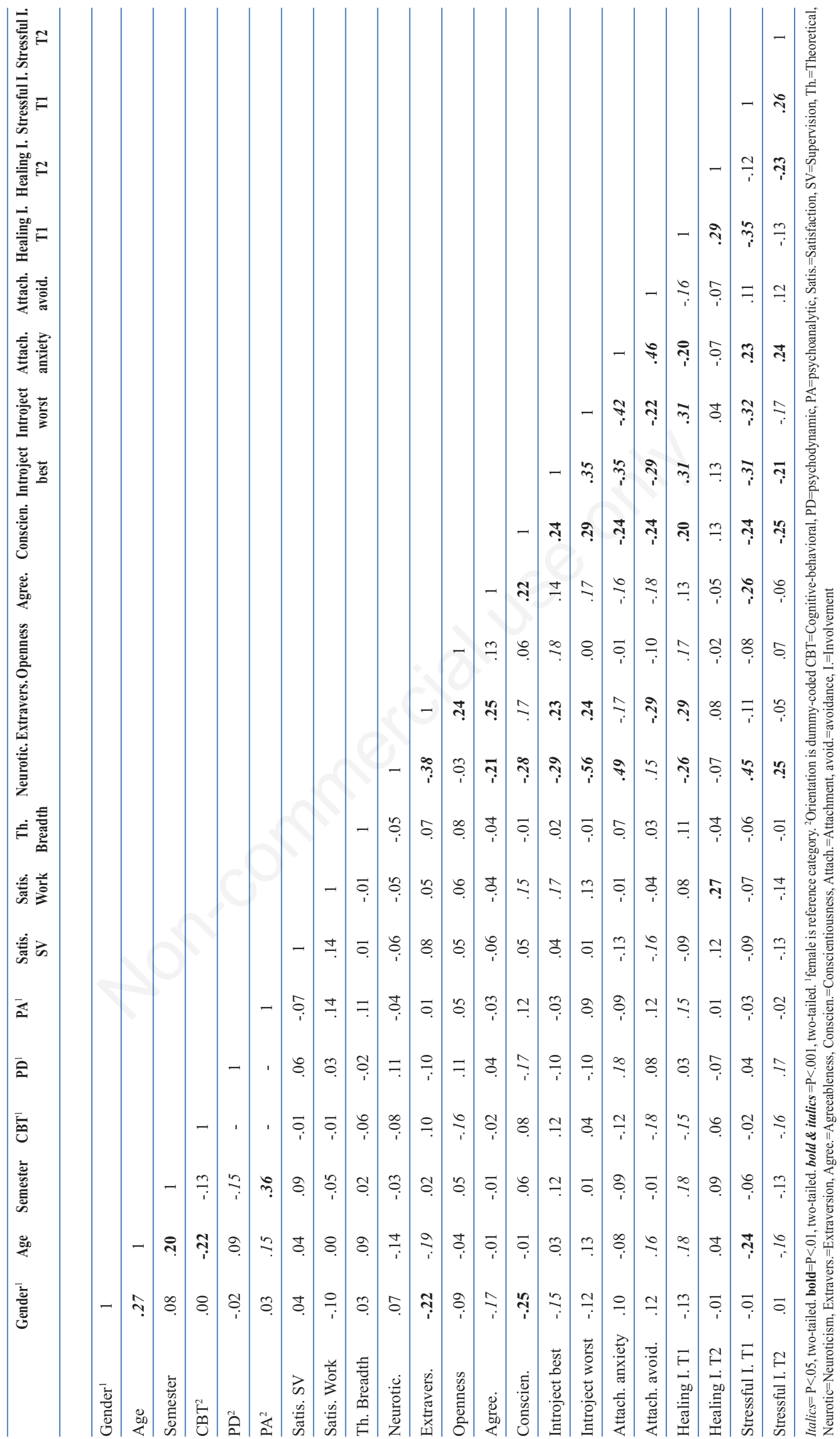


and professional attributes). This study found different sets of predictors for Healing and Stressful Involvement. Healing Involvement was largely predicted by training context and professional attributes (orientation, work satisfaction) and only one significant predictor from the domain of personal attributes (extraversion). Stressful Involvement, on the other hand, was exclusively predicted by personal attributes of trainees (neuroticism, conscientiousness, introject affiliation) and one sociodemographic characteristic (age). These results highlight that Healing and Stressful Involvement develop differently in psychotherapy training and that there might be distinct variables of influence involved in this development.

Our finding that Healing Involvement increased over three years of training is consistent with previous crosssectional and short longitudinal studies (Dennhag \& Ybrandt, 2013; Orlinsky \& Rønnestad, 2005; Taubner et al., 2013); in addition to that no trainees deteriorated reliably on Healing Involvement (which partially differs from the findings by Dennhag \& Ybrandt, 2013). This means that no trainee showed a relevant decrease in the amount of self-rated positive relational behaviors with clients and constructive coping strategies in the face of difficulties. This could be due to the longer observation period in the current study, as deteriorations over a short time span might represent developmental crises that get resolved during longer training processes (Rønnestad et al., 2019; Rønnestad \& Skovholt, 2013). This positive development was not reduced by the high number of trainees who showed no reliable change because the majority of trainees with lower initial levels of Healing Involvement appeared to improve over training, while a large percentage of the other trainees was already above the cutoff for high Healing Involvement at the beginning of the study.

A finding that is somewhat worrying is that the high amount of Stressful Involvement in trainees did not decrease over three years of training. These results confirm trends shown in the literature (Dennhag \& Ybrandt, 2013),

Table 4. Multilevel models predicting work involvement.

\begin{tabular}{|c|c|c|c|c|c|c|}
\hline \multirow[b]{2}{*}{ Predictor } & \multicolumn{3}{|c|}{ Healing Involvement } & \multicolumn{3}{|c|}{ Stressful Involvement } \\
\hline & B & $95 \%$ CI & $\mathbf{P}$ & B & $95 \%$ CI & $\mathbf{P}$ \\
\hline Intercept & 8.22 & $6.14-10.31$ & $<.001$ & 7.69 & $5.04-10.33$ & $<.001$ \\
\hline Time & 1.09 & $0.76-1.42$ & $<.001$ & -0.30 & $-0.78-0.18$ & .22 \\
\hline \multicolumn{7}{|l|}{ Covariate } \\
\hline Gender (Male) & -0.07 & $-0.45-0.30$ & .70 & -0.08 & $-0.55-0.40$ & .76 \\
\hline Age & 0.02 & $-0.00-0.04$ & .09 & -0.04 & $-0.06--0.01$ & .008 \\
\hline Semester & 0.06 & $-0.02-0.13$ & .14 & -0.03 & $-0.13-0.06$ & .49 \\
\hline \multicolumn{7}{|c|}{ Training Context } \\
\hline \multicolumn{7}{|l|}{ Orientation } \\
\hline $\mathrm{PD}^{1}$ & 0.35 & $-0.02-0.72$ & .06 & 0.04 & $-0.45-0.53$ & .88 \\
\hline $\mathrm{PA}^{1}$ & 0.49 & $0.00-0.98$ & .05 & 0.09 & $-0.57-0.74$ & .80 \\
\hline Supervision (Satisfaction) & -0.06 & $-0.20-0.08$ & .39 & -0.13 & $-0.30-0.04$ & .14 \\
\hline \multicolumn{7}{|l|}{ Professional attributes } \\
\hline Work Satisfaction & 0.02 & $0.00-0.04$ & .02 & -0.01 & $-0.04-0.01$ & .29 \\
\hline Theoretical Breadth & 0.01 & $-0.08-0.09$ & .90 & -0.02 & $-0.13-0.09$ & .71 \\
\hline \multicolumn{7}{|c|}{ Personal attributes } \\
\hline \multicolumn{7}{|l|}{ Personality traits } \\
\hline Neuroticism & 0.00 & $-0.02-0.02$ & .83 & 0.05 & $0.03-0.08$ & $<.001$ \\
\hline Extraversion & 0.03 & $0.00-0.06$ & .04 & 0.02 & $-0.01-0.06$ & .20 \\
\hline Openness to experience & 0.00 & $-0.02-0.03$ & .97 & 0.00 & $-0.03-0.04$ & .79 \\
\hline Agreeableness & -0.01 & $-0.04-0.02$ & .45 & -0.03 & $-0.07-0.00$ & .07 \\
\hline Conscentiousness & 0.02 & $-0.01-0.04$ & .26 & -0.04 & $-0.07-0.00$ & .04 \\
\hline \multicolumn{7}{|l|}{ Introject affiliation } \\
\hline At best & 0.01 & $0.00-0.01$ & .08 & -0.01 & $-0.02-0.00$ & .02 \\
\hline At worst & 0.00 & $0.00-0.00$ & .62 & 0.00 & $0.00-0.01$ & .87 \\
\hline \multicolumn{7}{|l|}{ Attachment } \\
\hline Anxiety & -0.01 & $-0.17-0.15$ & .89 & -0.01 & $-0.21-0.19$ & .94 \\
\hline Avoidance & -0.06 & $-0.24-0.13$ & .51 & 0.03 & $-0.21-0.26$ & .84 \\
\hline \multicolumn{7}{|l|}{ Interactions } \\
\hline Time $x \mathrm{PD}^{1}$ & -0.44 & $-0.87--0.01$ & .05 & 0.52 & $0.11-1.15$ & .11 \\
\hline Time $x \mathrm{PA}^{1}$ & -0.67 & $-1.32--0.11$ & .02 & 0.35 & $-0.47-1.17$ & .41 \\
\hline Explained Variance & & $0.559 ; \Omega_{0}^{2}=0$ & & & $0.383 ; \Omega_{0}^{2}=0$ & \\
\hline
\end{tabular}

PD, psychodynamic; PA, psychoanalytic. ${ }^{1}$ Reference category: Cognitive behavioral. 
and further highlight that these negative trends persist over the whole course of psychotherapy training. This persistence in high Stressful Involvement could be explained by predominant feelings of anxiety, insufficiency, and self-criticism among psychotherapy trainees that have been shown in qualitative studies (Hill et al., 2007; Kannan \& Levitt, 2017; Rønnestad \& Skovholt, 2013) as well as financial pressures that have been reported in representative surveys of German trainees (Klein-Schmeink, 2017; Strauß et al., 2009). Taken together, these challenging aspects of training might carry a risk for continued negative developmental processes (Rønnestad et al., 2019) among a larger number of trainees than previously thought.

Among the predictors of work involvement, trainee personality played an unexpectedly large role, especially with regard to Stressful Involvement. This finding is noteworthy since trainee personality has received comparatively little attention in the research of therapist characteristics (cf. Hill \& Castonguay, 2017). While there is no study on the direct effects of personality on work involvement, our finding that extraversion predicted Healing involvement while neuroticism predicted Stressful Involvement goes in line with studies in the general population. Extraversion encompasses attributes such as enthusiasm, optimism, and confidence (Goldberg, 1990) and predicted positive affect and subjective well-being in population studies (DeNeve \& Cooper, 1998; Hayes \& Joseph, 2003). Meanwhile, neuroticism is defined as a general disposition for more anxiousness and negativity (Goldberg, 1990) and is associated with a higher negative affect, lower life satisfaction, and less subjective well-being in the general population (DeNeve \& Cooper, 1998; Hayes \& Joseph, 2003). Thus, these personality attributes might be parts of larger cycles of professional growth and depletion by fostering positive or negative attitudes towards professional development (Orlinsky \& Rønnestad, 2005). Lastly, in our study conscientiousness had a negative association with Stressful Involvement and can be seen as a protective factor because it might prevent avoidant coping strategies that are associated with Stressful Involvement such as passively waiting for improvement (ibid.).

In the realm of professional and training attributes that predict work involvement, trainee orientation had a substantial effect that has not previously been reported. At the beginning of training, CBT-trainees were lower in Healing Involvement than psychoanalytic and psychodynamic trainees. These differences were compensated during the training (Figure 1). This finding may be the result of differences in personal motives for choosing either type of training (Strauß \& Kohl, 2009b). Previous studies comparing the two groups have found a stronger focus on the therapeutic relationship among psychodynamically oriented trainees (Nikendei et al., 2018) as well as a higher interest in the motives for interpersonal behavior (Taubner et al., 2014), which could be associated with interpersonal aspects of Healing Involvement.
A number of variables that were associated with work involvement in previous studies or could be expected to predict professional development had no significant effect in this investigation. Cross-sectional results that highlighted the importance of theoretical breadth (Orlinsky \& Rønnestad, 2005) could not be replicated in our study, which might be due to the composition of the sample. While this study focused on trainees, Orlinsky and Rønnestad (2005) included therapists from all career stages. Thus, the positive effect of theoretical breadth might come into play during later stages of professional development. Furthermore, attachment strategies had no influence on work involvement. These results are contrary to studies of therapist characteristics that imply a significant role of therapist attachment in the therapy process (Strauß \& Petrowski, 2017). Empirically, this might be explained by the significant correlation between personality traits and attachment strategies that has also been shown in other investigations (Noftle \& Shaver, 2006). Among the two interrelated constructs, personality traits might have a more significant influence on work involvement than attachment, even though our results do not justify final conclusions about the shared variance of both constructs. Additionally, these results highlight that significant therapist characteristics for treatment process and outcome are not necessarily good predictors of professional development, and vice-versa.

\section{Implications for training}

Our findings show significant differences regarding the amount of change on Healing and Stressful Involvement in training that have implications for the design of training programs. The results that Healing Involvement improved in this study while Stressful Involvement did not change significantly, suggest that psychotherapy train-

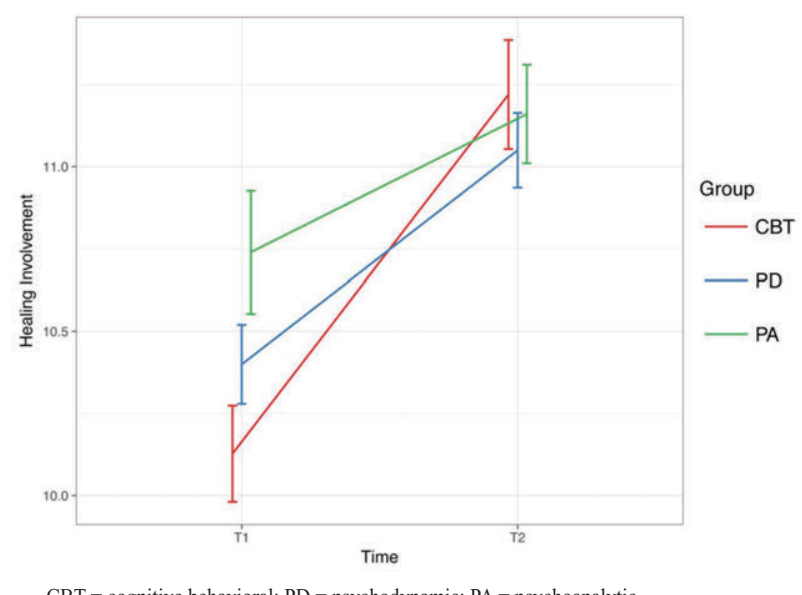

$\mathrm{CBT}=$ cognitive behavioral; $\mathrm{PD}=$ psychodynamic; $\mathrm{PA}=$ psychoanalytic.

Figure 1. Pre and Post change of Healing Involvement according to therapeutic orientation. 
ings similar to the ones investigated in this paper might be more effective in supporting the development of resources than in overcoming problems and challenges in the therapeutic process. Modularized psychotherapy training programs that have been investigated in this study might not be sufficient for addressing and reflecting on challenges in psychotherapeutic work that stretch over the whole duration of training (c.f. Rønnestad et al., 2019). Addressing these challenges would require organizing psychotherapy training by developmental tasks and not by content-based modules (Evers \& Taubner, in press). This could include tailored and adaptive training, a stronger connection between didactic and practical elements of training (e.g. Safran \& Muran, 2003) as well as mentoring structures that stretch across the whole training process (Bowers, Gauron, \& Mines, 1984; Vakoch \& Strupp, 2000) and use of methods like feedback and deliberate practice (Caspar, 2017; Evers \& Taubner, 2018; Rousmaniere, 2017). Finally, the strong connection between personal attributes of trainees and Stressful Involvement, might necessitate training methods that build bridges between personal and professional development such as self-practice/self-reflection (Bennett-Levy, 2019).

The set of personal predictors for Healing and Stressful Involvement might contain indicators for trainee selection, especially with regard to personality traits. Previous researchers have pointed towards the need for evidence-based trainee selection (Hill \& Knox, 2013). However, using the personality traits identified in this study for trainee selection would pose two major challenges. First, there is an ongoing debate about measuring invariance of personality assessment questionnaires in high stakes situations (Ion \& Iliescu, 2017) and recommendations from organizational psychology caution against the use of public available personality scales in personnel selection (Morgeson et al., 2007). Second, the personality traits predicting professional development found in this study do not correspond to predictors of positive psychotherapy process and outcome (Chapman et al., 2009; de la Fuente Zepeda \& Cruz del Castillo, 2017; Finlay, 2018; Peter et al., 2017), which could result in selection processes that promote professional development while having negative effects on psychotherapy outcome. Thus, our study points towards the usefulness of including personal attributes in future trainee selection processes, if measurement limitations can be overcome and if the selection criteria keep both the trainees' development and the treatment process in mind.

\section{Limitations}

Similar to most studies on psychotherapy training, this study was conducted in a naturalistic setting, which limits the extent to which we can draw firm conclusions on causal effects. Moreover, only self-report measures of professional were used. A further methodological limitation could be the dropout rate of about $30 \%$. Yet, no sub- stantial differences between dropouts and completers were found on the predictor and outcome variables and the final sample size and observation period are still significantly greater than in most training studies (Hill \& Knox, 2013). Regarding generalizability of the findings, the German training setting in which this study was conducted shows a decent overlap with many European countries (Strauß \& Kohl, 2009a) but differs significantly from graduate programs in university settings (see method section for details).

\section{Conclusions}

The current study showed a high level and an overall increase in Healing Involvement over three years of training, while Stressful Involvement stagnated at a high level. Furthermore, we found two sets of predictors for work involvement. Healing Involvement was mainly responsive to training variables and professional attributes, while Stressful Involvement was influenced by personal attributes only. These findings suggest that new training approaches should address more effectively trainees' professional challenges, perhaps by starting from the variables we found to predict work involvement in the aim of tailoring training programs and trainee selection.

\section{References}

Ackerman, S. J., \& Hilsenroth, M. J. (2001). A review of therapist characteristics and techniques negatively impacting the therapeutic alliance. Psychotherapy: Theory, Research, Practice, Training, 38(2), 171-185. doi: 10.1037/0033-3204.38.2.171

Ackerman, S. J., \& Hilsenroth, M. J. (2003). A review of therapist characteristics and techniques positively impacting the therapeutic alliance. Clinical Psychology Review, 23(1), 1-33. doi:10.1016/S0272-7358(02)00146-0

Anderson, T., \& Hill, C. E. (2017). The role of therapist skills in therapist effectiveness. In L. G. Castonguay \& C. E. Hill (Eds.), How and Why Are Some Therapists Better Than Others? Understanding Therapist Effects (pp. 139-157). Washington, DC: American Psychological Association.

Barnfield, T. V., Mathieson, F. M., \& Beaumont, G. R. (2007). Assessing the development of competence during postgraduate Cognitive-Behavioral Therapy training. Journal of Cognitive Psychotherapy, 21(2), 140-147.

Benjamin, L. S. (1974). Structural analysis of social behavior. Psychological Review, 81(5), 392-425. doi:10.1037/ h0037024

Benjamin, L. S. (1995). SASB Intrex short form user's manual. Salt Lake City, UT: University of Utah.

Benjamin, L. S., Rothweiler, J. C., \& Critchfield, K. L. (2006). The use of Structural Analysis of Social Behavior (SASB) as an assessment tool. Annual Review of Clinical Psychology, 2(1), 83-109. doi:10.1146/annurev.clinpsy. 2.022305 .095337

Bennett-Levy, J. (2019). Why therapists should walk the talk: The theoretical and empirical case for personal practice 
in therapist training and professional development. Journal of Behavior Therapy and Experimental Psychiatry, 62, 133-145. doi:10.1016/j.jbtep.2018.08.004

Bennett-Levy, J., \& Beedie, A. (2007). The ups and downs of cognitive therapy training: What happens to trainees' perception of their competence during a cognitive therapy training course? Behavioural and Cognitive Psychotherapy, 35(1), 61-75. doi:10.1017/S13524658060 03110

Borkenau, P., \& Ostendorf, F. (1993). NEO-Fünf-Faktoren Inventar:(NEO-FFI); nach Costa und McCrae. Göttingen: Hogrefe.

Bowers, W. A., Gauron, E. F., \& Mines, R. A. (1984). Training of group psychotherapists: An evaluation procedure. Small Group Research, 15(1), 125-137. doi:10.1177/ 104649648401500107

Caspar, F. (2017). Professional expertise in psychotherapy. In L. G. Castonguay \& C. E. Hill (Eds.), How and why are some therapists better than others? Understanding therapist effects (pp. 193-214). Washington, DC: American Psychological Association.

Chapman, B. P., Talbot, N., Tatman, A. W., \& Britton, P. C. (2009). Personality traits and the working alliance in psychotherapy trainees: An organizing role for the Five Factor Model? Journal of Social and Clinical Psychology, 28(5), 577-596. doi:10.1521/jscp.2009.28.5.577

Collyer, H., Eisler, I., \& Woolgar, M. (2019). Systematic literature review and meta-analysis of the relationship between adherence, competence and outcome in psychotherapy for children and adolescents. European Child \& Adolescent Psychiatry. doi:10.1007/s00787018-1265-2

Costa, P. T., \& McCrae, R. R. (1992). Revised NEO Personality Inventory (NEO-PI-R) and NEO Five Factor Inventory. Professional manual. Odessa, FL: Psychological Assessment Resources.

de la Fuente Zepeda, J., \& Cruz del Castillo, C. (2017). Personalidad, experiencia y formación del psicoterapeuta como predictor de la alianza terapéutica [Personality, experience and psychotherapeutic training as predictor of the therapeutic relationship]. Psicología Iberoamericana, 25(2), 17-25.

DeNeve, K. M., \& Cooper, H. (1998). The happy personality: A meta-analysis of 137 personality traits and subjective well-being. Psychological Bulletin, 124(2), 197-229. doi:10.1037/0033-2909.124.2.197

Dennhag, I., \& Ybrandt, H. (2013). Trainee psychotherapists' development in self-rated professional qualities in training. Psychotherapy, 50(2), 158-166. doi:10.1037/ a0033045

Ehrenthal, J. C., Dinger, U., Lamla, A., Funken, B., \& Schauenburg, H. (2009). Evaluation der deutschsprachigen Version des Bindungsfragebogens „Experiences in Close Relationships - Revised” (ECR-RD). [Evaluation of the German version of the attachment questionnaire „Experiences in Close Relationships - Revised” (ECRRD)]. Psychotherapie, Psychosomatik, Medizinische Psychologie, 59(06), 215-223. doi:10.1055/s-20081067425

Elliott, R., Bohart, A. C., Watson, J. C., \& Murphy, D. (2018). Therapist empathy and client outcome: An updated metaanalysis. Psychotherapy, 55(4), 399-410. doi:10.1037/ pst0000175
Evers, O., \& Taubner, S. (2018). Feedback in der Psychotherapieausbildung. [Feedback in psychotherapy training]. Psychotherapeut, 63(6), 465-472. doi:10.1007/s00278018-0311-3

Evers, O., \& Taubner, S. (in press). Kompetenzentwicklung in der Psychotherapieausbildung [Competence development in psychotherapy training]. Psychotherapie im $\mathrm{Di}$ alog.

Farber, B. A., Suzuki, J. Y., \& Lynch, D. A. (2018). Positive regard and psychotherapy outcome: A meta-analytic review. Psychotherapy, 55(4), 411-423. doi:10.1037/ pst0000171

Fincke, J. I., Möller, H., \& Taubner, S. (2015). Does interpersonal behavior of psychotherapy trainees differ in private and professional relationships? Frontiers in Psychology, 6, 765. doi:10.3389/fpsyg.2015.00765

Finlay, M. (2018). The relationship between psychotherapist personality and therapeutic alliance. (Doctoral dissertation), Loma Linda, CA: Loma Linda University.

Goldberg, L. R. (1990). An alternative 'description of personality': The Big-Five factor structure. Journal of Personality and Social Psychology, 59(6), 1216-1229. doi:10.1037/0022-3514.59.6.1216

Hayes, N., \& Joseph, S. (2003). Big 5 correlates of three measures of subjective well-being. Personality and Individual Differences, 34(4), 723-727. doi:10.1016/ S0191-8869(02)00057-0

Heinonen, E., Knekt, P., Jääskeläinen, T., \& Lindfors, O. (2014). Therapists' professional and personal characteristics as predictors of outcome in long-term psychodynamic psychotherapy and psychoanalysis. European Psychiatry, 29(5), 265-274. doi:10.1016/j.eurpsy.2013. 07.002

Heinonen, E., Lindfors, O., Härkänen, T., Virtala, E., Jääskeläinen, T., \& Knekt, P. (2013). Therapists' professional and personal characteristics as predictors of working alliance in short-term and long-term psychotherapies. Clinical Psychology \& Psychotherapy, 21(6), 475-494. doi:10.1002/cpp.1852

Heinonen, E., Lindfors, O., Laaksonen, M. A., \& Knekt, P. (2012). Therapists' professional and personal characteristics as predictors of outcome in short- and long-term psychotherapy. Journal of Affective Disorders, 138(3), 301-312. doi:10.1016/j.jad.2012.01.023

Henrich, G., \& Herschbach, P. (2000). Questions on Life Satisfaction (FLZM) - A short questionnaire for assessing subjective quality of life. European Journal of Psychological Assessment, 16(3), 150-159. doi:10.1027//10155759.16.3.150

Henry, W. P., Schacht, T. E., Strupp, H. H., Butler, S. F., \& Binder, J. L. (1993). Effects of training in time-limited dynamic psychotherapy: Mediators of therapists' responses to training. Journal of Consulting and Clinical Psychology, 61(3), 441-447. doi:10.1037/0022-006X.61. 3.441

Hill, C. E., \& Castonguay, L. G. (2017). Therapist effects: integration and conclusion. In L. G. Castonguay \& C. E. Hill (Eds.), How and Why Are Some Therapists Better Than Others? Understanding Therapist Effects (pp. 325-341). Washington, DC: American Psychological Association.

Hill, C. E., \& Knox, S. (2013). Training and supervision in psychotherapy. In M. J. Lambert (Ed.), Bergin and Garfiled's Handbook of Psychotherapy and Behavior 
Change (6 ed., pp. 775-811). Hoboken, NJ: John Wiley \& Sons, Inc.

Hill, C. E., Sullivan, C., Knox, S., \& Schlosser, L. Z. (2007). Becoming psychotherapists: Experiences of novice trainees in a beginning graduate class. Psychotherapy: Theory, Research, Practice, Training, 44(4), 434-449. doi:10.1037/0033-3204.44.4.434

Hilsenroth, M. J., Defife, J. A., Blagys, M. D., \& Ackerman, S. J. (2006). Effects of training in short-term psychodynamic psychotherapy: Changes in graduate clinician technique. Psychotherapy Research, 16(3), 293-305. doi:10.1080/10503300500264887

Ion, A., \& Iliescu, D. (2017). The measurement equivalence of personality measures across high- and low-stake test taking settings. Personality and Individual Differences, 110, 1-6. doi:10.1016/j.paid.2017.01.008

Jacobson, N. S., \& Truax, P. (1991). Clinical significance: A statistical approach to defining meaningful change in psychotherapy research. Journal of Consulting and Clinical Psychology, 59(1), 12-19. doi:10.1037/0022-006X. 59.1 .12

Kannan, D., \& Levitt, H. M. (2017). Self-criticism in therapist training: A grounded theory analysis. Psychotherapy Research, 27(2), 201-214. doi:10.1080/10503307. 2015.1090036

Kenward, M. G., \& Roger, J. H. (1997). Small sample inference for fixed effects from Restricted Maximum Likelihood. Biometrics, 53(3), 983-997. doi:10.2307/2533558

Klein-Schmeink, M. (2017). Was beschäftigt PiA? Ausgewählte Ergebnisse der Umfrage von Maria KleinSchmeink, Mitglied des Deutschen Bundestages [What are psychotherapy trainee preoccupied with? Selected results of a survey by Maria Klein-Schmeink, MP]. Berlin.

Kolden, G. G., Wang, C.-C., Austin, S. B., Chang, Y., \& Klein, M. H. (2018). Congruence/genuineness: A metaanalysis. Psychotherapy, 55(4), 424-433. doi:10.1037/ pst0000162

Körner, A., Geyer, M., \& Brähler, E. (2002). Das NEO-FünfFaktoren Inventar (NEO-FFI) [The NEO Five Factor Inventory]. Diagnostica, 48(1), 19-27. doi:10.1026//00121924.48.1.19

Messina, I., Gelo, O. C. G., Sambin, M., Bianco, F., Mosconi, A., Fenelli, A., . . Orlinsky, D. (2018). Trainees' selfevaluation of their development as psychotherapists: An italian contribution to an international collaborative study on psychotherapy training. Clinical Psychology \& Psychotherapy, 25, 338-347. doi:10.1002/cpp.2165

Morgeson, F. P., Campion, M. A., Dipboye, R. L., Hollenbeck, J. R., Murphy, K., \& Schmitt, N. (2007). Reconsiderung the use of personality tests in personnel selection contexts. Personnel Psychology, 60(3), 683729. doi:10.1111/j.1744-6570.2007.00089.x

Navia, C. E., \& Arias, E. M. (2012). Alianza terapéutica y su relación con las variables de apego del terapeuta y del consultante. [Therapist and client attachment and its relationship with therapeutic alliance]. Universitas Psychologica, 11(3), 885-894.

Nikendei, C., Bents, H., Dinger, U., Huber, J., Schmid, C., Montan, I., . . Safi, A. (2018). Erwartungen psychologischer Psychotherapeuten zu Beginn ihrer Ausbildung [Expectations of psychological psychotherapists at the beginning of training]. Psychotherapeut, 63(6), 445-457. doi:10.1007/s00278-018-0312-2
Nissen-Lie, H. A., Monsen, J. T., \& Rønnestad, M. H. (2010). Therapist predictors of early patient-rated working alliance: A multilevel approach. Psychotherapy Research, 20(6), 627-646. doi:10.1080/10503307.2010.497633

Nissen-Lie, H. A., Monsen, J. T., Ulleberg, P., \& Rønnestad, M. H. (2013). Psychotherapists' self-reports of their interpersonal functioning and difficulties in practice as predictors of patient outcome. Psychotherapy Research, 23(1), 86-104. doi:10.1080/10503307.2012.735775

Nissen-Lie, H. A., Rønnestad, M. H., Høglend, P. A., Havik, O. E., Solbakken, O. A., Stiles, T. C., \& Monsen, J. T. (2017). Love yourself as a person, doubt yourself as a therapist? Clinical Psychology \& Psychotherapy, 24(1), 48-60. doi:10.1002/cpp.1977

Noftle, E. E., \& Shaver, P. R. (2006). Attachment dimensions and the big five personality traits: Associations and comparative ability to predict relationship quality. Journal of Research in Personality, 40(2), 179-208. doi:10.1016/j. jrp.2004.11.003

Norcross, J. C., \& Lambert, M. J. (2018). Psychotherapy relationships that work III. Psychotherapy, 55(4), 303-315. doi: $10.1037 /$ pst0000193

Orlinsky, D. E., \& Rønnestad, M. H. (Eds.). (2005). How psychotherapists develop : a study of therapeutic work and professional growth (1st ed.). Washington, DC: American Psychological Association.

Peter, B., Böbel, E., Hagl, M., Richter, M., \& Kazén, M. (2017). Personality styles of German-speaking psychotherapists differ from a norm, and male psychotherapists differ from their female colleagues. Frontiers in Psychology, 8(840). doi:10.3389/fpsyg.2017.00840

Pincus, A. L., Newes, S. L., Dickinson, K. A., \& Ruiz, M. A. (1998). A comparison of three indexes to assess the dimensions of Structural Analysis of Social Behavior. Journal of Personality Assessment, 70(1), 145-170. doi:10.1207/s15327752jpa7001_10

Rønnestad, M. H., Orlinsky, D. E., Schröder, T. A., Skovholt, T. M., \& Willutzki, U. (2019). The professional development of counsellors and psychotherapists: Implications of empirical studies for supervision, training and practice. Counselling and Psychotherapy Research, 19(3), 214230. doi:10.1002/capr.12198

Rønnestad, M. H., \& Skovholt, T. M. (2013). The developing practitioner: growth and stagnation of therapists and counselors. New York: Routledge.

Rousmaniere, T. (2017). Deliberate practice for psychotherapists. New York: Routledge.

Safran, J. D., \& Muran, J. C. (2003). Negotiating the therapeutic alliance: a relational treatment guide. New York: Guilford Press.

Sandell, R., Carlsson, J., Schubert, J., Broberg, J., Lazar, A., \& Grant, J. (2004). Therapist attitudes and patient outcomes: I. Development and validation of the Therapeutic Attitudes Scales (TASC-2). Psychotherapy Research, 14(4), 469-484. doi:10.1093/ptr/kph039

Sandell, R., Taubner, S., Rapp, A., Visbeck, A., \& Kächele, H. (2008). Psycho-Therapeutische Haltung Ausbildungsversion (ThAt-AV) [Therapeutic Attitudes Scales Trainee Version]. Ulm.

Schauenburg, H., Buchheim, A., Beckh, K., Nolte, T., BrenkFranz, K., Leichsenring, F., . . . Dinger, U. (2010). The influence of psychodynamically oriented therapists' attachment representations on outcome and alliance in in- 
patient psychotherapy. Psychotherapy Research, 20(2), 193-202. doi:10.1080/10503300903204043

Strauß, B. (2009). Patterns of psychotherapeutic practice and professionalisation in Germany. European Journal of Psychotherapy \& Counselling, 11(2), 141-150. doi:10.1080/13642530902927352

Strauß, B., Barnow, S., Brähler, E., Fegert, J., Fliegel, S., Freyberger, H. J., . . Willutzki, U. (2009). Forschungsgutachten zur Ausbildung von Psychologischen PsychotherapeutInnen und Kinder- und JugendlichenpsychotherapeutInnen [Research report on the training of psychological psychotherapists and child and youth psychotherapists]. Berlin: Bundesministerium für Gesundheit.

Strauß, B., \& Kohl, S. (2009a). Entwicklung der Psychotherapie und der Psychotherapieausbildung in europäischen Ländern [Development of psychotherapy and psychotherapy training in European countries]. Psychotherapeut, 54(6), 457. doi:10.1007/s00278-009-0703-5

Strauß, B., \& Kohl, S. (2009b). Themen der Ausbildungsforschung in der Psychotherapie [Issues of research in psychotherapy training]. Psychotherapeut, 54(6), 411. doi:10.1007/s00278-009-0710-6

Strauß, B., \& Petrowski, K. (2017). The role of the therapist's attachment in the process and outcome of psychotherapy. In L. G. Castonguay \& C. E. Hill (Eds.), How and why are some therapists better than others. Washington, DC: American Psychological Association.

Taubner, S., Munder, T., Möller, H., Hanke, W., \& Klasen, J. (2014). Selbstselektionsprozesse bei der Wahl des therapeutischen Ausbildungsverfahrens: Unterschiede in therapeutischen Haltungen, Persönlichkeitseigenschaften und dem Mentalisierungsinteresse. [Self-Selection processes in the choice of the therapeutic training ap- proach: differences in therapeutic attitudes, personality traits and attributional complexity]. Psychother Psych Med, 64(06), 214-223. doi:10.1055/s-0033-1358720

Taubner, S., Zimmermann, J., Kächele, H., Möller, H., \& Sell, C. (2013). The relationship of introject affiliation and personal therapy to trainee self-efficacy: A longitudinal study among psychotherapy trainees. Psychotherapy, 50(2), 167-177. doi:10.1037/a0029819

Vakoch, D. A., \& Strupp, H. H. (2000). The evolution of psychotherapy training: Reflections on manual-based learning and future alternatives. Journal of Clinical Psychology, 56(3), 309-318. doi:10.1002/(SICI)10974679(200003)56:3<309::AID-JCLP7>3.0.CO;2-7

Wampold, B. E., Baldwin, S. A., grosse Holtforth, M., \& Imel, Z. E. (2017). What characterizes effective therapists? In L. G. Castonguay \& C. E. Hill (Eds.), How and why are some therapists better than others? Understanding therapist effects (pp. 37-54). Washington, DC: American Psychological Association.

Webb, C. A., DeRubeis, R. J., \& Barber, J. P. (2010). Therapist adherence/competence and treatment outcome: A meta-analytic review. Journal of Consulting and Clinical Psychology, 78(2), 200-211. doi:10.1037/a0018912

Willutzki, U., Fydrich, T., \& Strauß, B. (2015). Aktuelle Entwicklungen in der Psychotherapieausbildung und der Ausbildungsforschung [Current developments in psychotherapy training and training research]. Psychotherapeut, 60(5), 353-364. doi:10.1007/s00278-015-0048-1

Zeeck, A., Orlinsky, D. E., Hermann, S., Joos, A., Wirsching, M., Weidmann, W., \& Hartmann, A. (2012). Stressful involvement in psychotherapeutic work: Therapist, client and process correlates. Psychotherapy Research, 22(5), 543-555. doi:10.1080/10503307.2012.683345 